\title{
Evaluation of Factors Affecting the Severity of Diabetic Foot Ulcer in Patients with Diabetes Referred to a Diabetes Centre in Kermanshah
}

This article was published in the following Dove Press journal: Diabetes, Metabolic Syndrome and Obesity: Targets and Therapy

\author{
Akram Ghobadi ${ }^{\prime}$ \\ Pegah Ahmadi Sarbarzeh ${ }^{2}$ \\ Milad Jalilian (1D ${ }^{2}$ \\ Alireza Abdi ${ }^{1}$ \\ Sara Manouchehri ${ }^{3}$ \\ 'Nursing Department, Nursing and \\ Midwifery School, Kermanshah University \\ of Medical Sciences, Kermanshah, Iran; \\ ${ }^{2}$ Nursing Department, Nursing and \\ Midwifery School, Student Research \\ Committee, Kermanshah University of \\ Medical Sciences, Kermanshah, Iran; \\ ${ }^{3}$ Biostatistics Department, Kermanshah \\ University of Medical Sciences, \\ Kermanshah, Iran
}

Introduction: Diabetes mellitus is a metabolic disease characterized by high blood sugar (BS) levels and the change in the metabolism of lipids, carbohydrates, and insulin resistance, and is one of the main causes of disability and mortality worldwide. Among the different types of complications, which have many negative effects on personal and social life, diabetic foot ulcer (DFU) is very important. This study aims to investigate the factors affecting the severity of DFU among patients with diabetes.

Methods: The study participants included 190 diabetic patients with a diagnosis of DFU. Data were collected using a two-part questionnaire for self-care awareness and functions in diabetic patients and Wagner's scale. The questionnaire was answered in cooperation with patients and the Wagner's score was estimated by a wound supervisor in the diabetes center.

Results: There was 109 women (57.4\%). Twenty-six patients had other diabetic complications as well as DFU. The average score of awareness in patients was $6.99 \pm 2.76$ and the function was $62.22 \pm 9.92$. The results found a direct relation between the age and the duration of illness with the score of the patient's awareness $(P=0.008, P=0.000)$. There was also a direct relation between the level of education with score of awareness and the score of function in self-care $(P=0.000, P=0.000)$, but the statistical results did not find any relation between awareness and the function in self-care of patients with the severity of DFU $(P>0.05)$.

Discussion: There was no relation between the self-care awareness and function with severity of DFU $(P>0.05)$ that can be due to the more relation between DFU severity with hygiene and physical factors after the disease and the effect of awareness and function would be only in the incidence of the DFU.

Conclusion: Awareness and function of patients in self-care is less than average. Increasing awareness of patients and empowering them through appropriate training can be effective in preventing diabetic foot ulcers.

Keywords: diabetes, diabetic foot ulcer, diabetes complications

\section{Introduction}

Diabetes mellitus is one of the most extensive epidemics the world has faced, both in developed and developing nations. ${ }^{1}$ The latest global estimate from the International Diabetes Federation is that in 2019 there were 463 million people with diabetes mellitus and that, by 2045 , the number will be 700 million. $^{2}$ And the WHO gave a similar estimate of 422 million in $2014 .^{3}$ Among the different types of diabetes complications, which have many negative effects on treatment
Correspondence: Pegah Ahmadi Sarbarzeh

Nursing Department, Nursing and

Midwifery School, Student Research

Committee, Kermanshah University of

Medical Sciences, Kermanshah, Iran

Tel +989301946547

Email Ahmadi.pegah554@yahoo.com 
costs and quality-of-life, diabetic foot ulcer (DFU) is very important. ${ }^{4}$ Diabetic foot ulcer is a full-thickness ulcer, skin necrosis or foot gangrene caused by peripheral neuropathy or peripheral arterial disease in patients with diabetes. ${ }^{5}$ In other words, DFU contains several diseases, mainly diabetic neuropathy and peripheral arterial disease that causes foot ulcers that may eventually lead to amputation, especially when it occurs with wound infection or osteomyelitis. ${ }^{6} \mathrm{DFU}$ is one of the most common, most severe, and expensive complications of diabetes and the major cause of hospitalization in the world. ${ }^{7}$ The DFU complication has a lot of economic effects on the patients and the health system; It is estimated that $24.4 \%$ of the total healthcare costs in the diabetic population are associated with the DFU and the total cost of treating the DFU is close to 11 billion in the US and 456 million dollars in the UK. ${ }^{8,10}$ In addition, the DFU is a cause of emotional and physical disorders that reduce a patient's quality-of-life. ${ }^{11}$ More than one million amputations occur worldwide each year, and almost half of all amputations are due to non-traumatic reasons, $80 \%$ of which is DFU. ${ }^{12}$

This problem is caused by a variety of factors, but, generally, factors such as peripheral ischemia, neuropathy, or a combination of different causes are known as causative factors. ${ }^{4}$ In 2016, the global DFU prevalence was $6.3 \%$, which was higher in males, and higher in type 2 diabetic patients. ${ }^{13}$ Atosona et al $^{14}$ show that the prevalence of diabetic foot ulcers DFU is $11 \%$ in Ghana. The annual incidence of DFU is $2-4 \% .{ }^{15}$ However, the relationship between demographic variables, BS, hyperlipidemia, and weight with DFU incidence has been reported in multiple studies, ${ }^{16,19}$ but no studies have been done about the relation between severity of the DFU and variables in these patients. One of the reasons that the patients do not control their diabetes well is a lack of awareness and poor function in their care. Also, other factors include lifestyle and demographical variables. It can be due to the lack of education systems in hospitals and lack of evidence-based studies about the factors affecting DFU severity. Therefore, due to the high prevalence of diabetes and the importance of DFU and its health and economic effects on the health system and patients with diabetes, as well as the lack of a similar study to investigate the factors affecting the severity of DFU, the present study aimed of determine the factors including lifestyle, demographical, and self-care affecting the severity of DFU.

\section{Methods}

\section{Study Design}

This was a cross-sectional study and approved by The Ethics Committee, Department of Research and Technology, Kermanshah University of Medical Sciences (approval number, IR.KUMS.REC.1397.025). This study was conducted in accordance with the Declaration of Helsinki. We collected samples from January 2019 to May 2019 and all the patients provided informed consent prior to sample withdrawal.

\section{Participants}

The study was performed on 190 patients with diabetic foot ulcers in the diabetes center of Kermanshah Province and patients with medical records in the Imam Reza hospital of Kermanshah within the first 5 months of 2019. The studied patients' age was more than 18 years and they were assured of the purpose of the study and their rights as well as provided written consent. They needed the ability to communicate effectively (verbal and non-verbal); so, patients with physical diseases unrelated to diabetes or mental diseases confirmed by the doctor and patients using effective nerve drugs were eliminated from the study.

According to the confidence level of $95 \%$ and $P=4 \%$ in the general population ${ }^{5}$ with G-Power software, the minimum number of required subjects was calculated as 151 and, by accounting the loss of subjects, this number was considered to be 170 individuals and, finally, 190 complete questionnaires were received from the patients.

\section{Data Collecting}

In order to collect data after obtaining the required permission, the research was referred to the diabetes center of Kermanshah Province and also to Imam Reza hospital of Kermanshah in which the patients have their membership documents at the diabetes center of Kermanshah Province. First, they assured of the confidentiality of participant's information and also about the purpose of the research and then the written consent was received. After that, they were given sufficient guidance to fill out the questionnaires. The questionnaires were self-reported, without the intervention of the researchers. In order to collect data on the awareness and function about self-care of the diabetic patients, the Wagner ulcer scale and the information form prepared by researchers were used.

The information form provided by the researchers has 13 questions about the history of the disease and the demographic variables of the subject. The information 
form, which was constructed by 12 faculty members of Kermanshah University of Medical Sciences, has been confirmed.

The awareness and the function about self-care questionnaire includes two parts to make the patient aware about diabetes and his performance in self-care functions. The first part of the questionnaire, the awareness part (Figure 1), includes individual's awareness about diabetes (7 questions), awareness about physical activity and exercise (4 questions), and about diet (5 questions). The awareness questionnaire includes questions that measure patient information (for example: diabetes causes, diabetes signs and symptoms, awareness about Complications of diabetes and how to control them, diabetes treatment, awareness about proper exercise and diet). In order to score the questions related to the awareness of each correct answer, every correct answer was given a score of one and wrong answers were given a score of zero. The second part of the questionnaire, function in self-care, includes the patient's knowledge of diet ( 7 questions), physical activity and exercise (6 questions), control of early complications (6 questions), control of late complications (5 questions), and foot care (5 questions). The function questionnaire score is designed on a Likert scale. Each question has five options and its score ranges from one-to-five (Figure 2).

In fact, the awareness questions are set to study awareness level. There is a score of one for every correct answer and a score of zero for any wrong answer and the total score of the test is between zero and 16. Questions related to the function in self-care in the Likert scale were scored from one-to-five. After completing the research tool by patients, the patients' self-care condition is determined based on the total number of scores received from each questionnaire. The function in self-care questions include five sections such as diet, exercise, control of early complications, control of late complications, and foot care. The total number of the function in self-care questions is between 29 and 145. This questionnaire was designed in 2009 by Farsi et $\mathrm{al}^{20}$ and in their studies its validity and reliability were measured. The validity of the test has been approved through content analysis and the comments of 15 professors of medical sciences have also been confirmed. The test-re-test was used for reliability, with the correlation coefficient between the two stages of the test estimated as $0.63-0.98$ with $T$-test and Wilcoxon. Besides, the internal consistency with Cronbach's alpha of the total test was calculated to be 0.66 .

Wagner ulcer scale is one of the oldest and most extensive categories in all types of ulcers. This scale categorizes diabetic foot ulcer on the basis of the ulcer depth into six scores: (1) grade 0: Skin is healthy; (2) grade 1: There is a superficial ulcer; (3) grade 2: There is a deep ulcer; (4) grade 3: Deep ulcer with abscess, bone involvement or osteomyelitis; (5) grade 4: Gangrene in the front or gangrene of the part of the limb (such as toe); (6) grade 5: General gangrene of the foot.

\section{Findings}

There was 109 women $(57.4 \%)$ from the total studied population (190 individuals). The results of the study found that $30.5 \%$ of patients have a family history of diabetes, of whom $32.75 \%$ (19 individuals or $10 \%$ of the research population) have reported diabetics symptoms in their family. Twenty-six patients $(13.7 \%)$, had other diabetic symptoms besides foot ulcers, such as cardiovascular complications (11 individuals, 5.8\%), eye problems (6 individuals, 3.2\%), kidney problems (2 individuals, $1.1 \%$ ), and other symptoms (7 individuals, 3.7\%) (Table 1). The results of the study of the severity of the ulcer are listed in Table 2. The results of the awareness study and the Function in self-care of subjects are described in Table 3 . The average total score of awareness in patients was $6.99 \pm 2.76$. The total of awareness is based on three items of patient awareness of diabetes, awareness of exercise and also physical activity as well as awareness of dietary compliance (Table 3 ). The average score of the function in self-care was $62.22 \pm 9.92$, which is based on five items (the patient's Function in dietary, exercise and physical activity, performance in the control of early complications and control of late complications and also function in foot care) (Table 3). One hundred and eleven individuals $(58.4 \%)$ received less than half of the awareness score, and for the function in self-care this rate was 176 individuals $(92.6 \%)$.

There was statistical analysis to find the relation between demographic variables with the awareness and function in self-care in patients. First, the normality of the data was studied through Kolmogorov-Smirnov test, which showed an abnormality of the data. So, the Spearman test was used to study the relation of quantity variables and Kruskal-Wallis and U Mann Whitney were used to study the relation of quality variables with awareness and the self-care function; the results found that there is a direct relation between age and the duration of the disease with the total score of the patient's awareness, such as awareness of disease, exercise, and diet $(P=0.008$, $P=0.000)$. There was also a direct relation between the 


\begin{tabular}{|c|c|}
\hline Awareness Questions & Answers \\
\hline \multicolumn{2}{|c|}{ Awareness about diabetes disease } \\
\hline 1. What is the most important cause of diabetes? & $\begin{array}{l}\text { A) Insulin deficiency or dysfunction } \\
\text { B) Increased insulin } \\
\text { C) Reduce blood sugar } \\
\text { D) Reduce blood lipids }\end{array}$ \\
\hline $\begin{array}{l}\text { 2. Which one of the following is a symptom of } \\
\text { diabetes? }\end{array}$ & $\begin{array}{l}\text { A) Polydipsia and polyphagia } \\
\text { B) Weight loss and dryness of the skin } \\
\text { C) Hyper hidrosis and polyuria } \\
\text { D) All cases }\end{array}$ \\
\hline $\begin{array}{l}\text { 3. Which one of the following is effective in } \\
\text { diabetes incidence? }\end{array}$ & $\begin{array}{l}\text { A) Control of blood sugar and lipids } \\
\text { B) Obesity, lack of exercise and physical activity } \\
\text { C) Walk for a long time } \\
\text { D) Control of stress }\end{array}$ \\
\hline $\begin{array}{l}\text { 4. Which one of the following should be avoided } \\
\text { to prevent complications? }\end{array}$ & $\begin{array}{l}\text { A) Control of blood sugar and lipids } \\
\text { B) Tobacco use } \\
\text { C) Control of blood pressure } \\
\text { D) Exercise and activity }\end{array}$ \\
\hline $\begin{array}{l}\text { 5. Which one of the following is most common } \\
\text { late complication of diabetes? }\end{array}$ & $\begin{array}{l}\text { A) Kidneys, Eyes, Heart - Vascular and Foot } \\
\text { B) Liver, Gastrointestinal and Nervous System } \\
\text { C) Musculoskeletal system } \\
\text { D) Gastrointestinal and immune system }\end{array}$ \\
\hline $\begin{array}{l}\text { 6. Which of the following person is most } \\
\text { susceptible to diabetes? }\end{array}$ & $\begin{array}{l}\text { A) Athletes and lean people } \\
\text { B) Obese people and people with a family history } \\
\text { C) People who have a lot of physical activity } \\
\text { D) Everyone is equally at risk. }\end{array}$ \\
\hline 7. What are the principles of diabetes treatment? & $\begin{array}{l}\text { A) Insulin use } \\
\text { B) Oral medications } \\
\text { C) Exercise, diet and medications } \\
\text { D) There is no cure for diabetes }\end{array}$ \\
\hline \multicolumn{2}{|c|}{ Awareness about exercise and physical activity } \\
\hline $\begin{array}{l}\text { 1. What is the best type of physical activity for } \\
\text { you? }\end{array}$ & $\begin{array}{l}\text { A) Walking } \\
\text { B) Basketball } \\
\text { C) football } \\
\text { D) track and field }\end{array}$ \\
\hline $\begin{array}{l}\text { 2. What should be observed before starting the } \\
\text { exercise? }\end{array}$ & $\begin{array}{l}\text { A) You should not eat food before starting } \\
\text { exercise } \\
\text { B) Eat foods or sugars before exercise } \\
\text { C) You should exercise for a long time } \\
\text { D) If symptoms of hypoglycemia occur during } \\
\text { exercise, it should not be considered }\end{array}$ \\
\hline $\begin{array}{l}\text { 3. What is the recommended time for exercise in } \\
\text { people with diabetes? }\end{array}$ & $\begin{array}{l}\text { A) at least } 15 \text { minutes - } 3 \text { times a week } \\
\text { B) at least } 3 \text { hours - daily } \\
\text { C) There is no restriction } \\
\text { D) Exercise is generally harmful to diabetics }\end{array}$ \\
\hline 4. Which one of the following is correct? & $\begin{array}{l}\text { A) Eating sugar before exercise is not necessary } \\
\text { B) There is no problem if you exercise the site of } \\
\text { insulin injection } \\
\text { C) A complete cardiac evaluation should be } \\
\text { performed in people with diabetes who have a } \\
\text { history of cardiovascular disease } \\
\text { D) Wearing shoes and socks is not restricted in } \\
\text { diabetics }\end{array}$ \\
\hline \multicolumn{2}{|c|}{$\begin{array}{r}\text { Awareness about Diet } \\
\end{array}$} \\
\hline $\begin{array}{l}\text { 1. Which one of the following foods are helpful to } \\
\text { you? }\end{array}$ & $\begin{array}{l}\text { A) High-fat foods } \\
\text { B) Fruits and vegetables } \\
\text { C) Cakes and pastries } \\
\text { D) All kinds of fruit cans }\end{array}$ \\
\hline $\begin{array}{l}\text { 2. Which of the following foods has no } \\
\text { restrictions for you and is safe to eat? }\end{array}$ & $\begin{array}{l}\text { A) Honey } \\
\text { B) Jam } \\
\text { C) Fish } \\
\text { D) Cream }\end{array}$ \\
\hline $\begin{array}{l}\text { 3. Which of the following drinks is forbidden to } \\
\text { you? }\end{array}$ & $\begin{array}{l}\text { A) Soda } \\
\text { B) Mineral water } \\
\text { C) Buttermilk } \\
\text { D) Low-fat milk }\end{array}$ \\
\hline 4. What should your diet be like? & $\begin{array}{l}\text { A) three times a day } \\
\text { B) high number meals and small volume meals } \\
\text { C) few number meals and large volume meals } \\
\text { D) small volume meals and few number meals }\end{array}$ \\
\hline $\begin{array}{l}\text { 5. Which one of the following foods is best for } \\
\text { you? }\end{array}$ & $\begin{array}{l}\text { A) Fried foods } \\
\text { B) Boiled foods } \\
\text { C) Canned foods } \\
\text { D) Veal }\end{array}$ \\
\hline
\end{tabular}

Figure I Awareness Questionnaire.

level of education with the total score of awareness and the total score of self-care function $(P=0.000, P=0.000)$ in such a way that it improved by increasing the education level, awareness, and the self-care function. Also, subjects' occupation was also related to their total awareness level $(P=0.002)$ (Tables 4 and 5). 


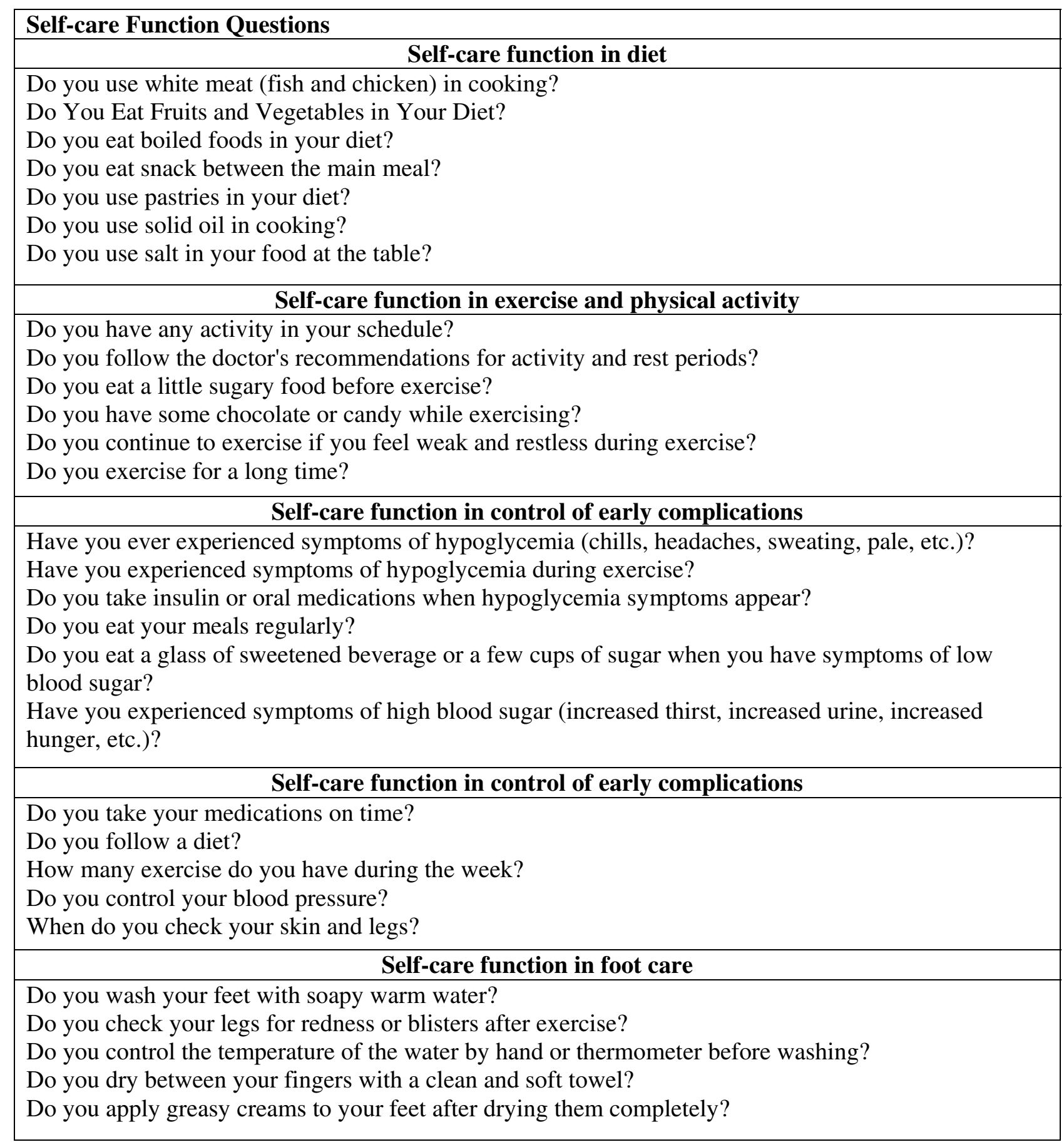

Figure 2 Function in Self-Care Questionnaire.

We used the Kruskal-Wallis test in order to determine the relation among variables of the awareness total score, the selfcare function total score, and the age and the duration of the disease with the severity of ulcer. The results found that none of the age and the duration of the disease variables were related to the severity of the ulcer $(P>0.05)$. Furthermore, although the low level of awareness and failure in the self-care function can cause inappropriate behavior with the disease and also lack of the disease control as well as the severity of symptoms, the statistical results did not find any relation between awareness and the self-care function of patients with the severity of foot ulcer $(P>0.05)$ (Table 6).

In order to study the relation of the quality variables with the severity of the ulcer, the chi-square test was 
Table I Qualitative Variables $(n=190)$

\begin{tabular}{|c|c|c|c|c|c|}
\hline Parameters & Values & n (\%) & Parameters & Values & $n(\%)$ \\
\hline \multirow[t]{2}{*}{ Gender } & Female & $109(57.4)$ & \multirow[t]{10}{*}{ Job } & Employee & $34(17.9)$ \\
\hline & Male & $81(42.6)$ & & Self-Employment & $20(10.5)$ \\
\hline \multirow[t]{4}{*}{ Marriage } & Single & 147 (77.4) & & Workless & $5(2.6)$ \\
\hline & Married & $16(8.4)$ & & Retired & $20(10.5)$ \\
\hline & Divorced & $19(10.0)$ & & Military & $5(2.6)$ \\
\hline & Widow & $8(4.2)$ & & Home Made & $71(37.4)$ \\
\hline \multirow[t]{5}{*}{ Education } & Illiterate & $35(18.4)$ & & Student & $8(4.2)$ \\
\hline & Elementary & $69(36.3)$ & & Farmer-Herdsman & $15(7.9)$ \\
\hline & Secondary Education & $51(26.8)$ & & Driver & $8(4.2)$ \\
\hline & High School & $19(10.0)$ & & Other & $4(2.1)$ \\
\hline & College & $16(8.4)$ & \multirow[t]{3}{*}{ Income (USD/Month) } & $<300$ & $162(85.3)$ \\
\hline \multirow[t]{2}{*}{ Location } & City & $139(73.2)$ & & $300-400$ & $23(12.1)$ \\
\hline & Village & $51(26.8)$ & & $>400$ & $5(2.6)$ \\
\hline \multirow[t]{2}{*}{ Family History of Diabetes } & Yes & $58(30.5)$ & \multirow[t]{2}{*}{ Diabetes Complications in Family } & Yes & $19(10.0)$ \\
\hline & No & $132(69.5)$ & & No & $|7|(90.0)$ \\
\hline \multirow[t]{4}{*}{ Type of OC } & Cardiovascular Comp. & II (5.8) & \multirow[t]{4}{*}{ Other Complications (OC) } & Yes & $26(13.7)$ \\
\hline & Eye Comp. & $6(3.2)$ & & \multirow[t]{3}{*}{ No } & \multirow[t]{3}{*}{$164(86.3)$} \\
\hline & Renal Comp. & $2(1.1)$ & & & \\
\hline & Other Comp. & $7(3.7)$ & & & \\
\hline
\end{tabular}

Table 2 Severity of Foot Ulcer (Wagner Scale) $(n=190)$

\begin{tabular}{|l|l|l|}
\hline Parameter & Values (Grade 0-5) & n (\%) \\
\hline Severity of Ulcer & No ulcer but foot at risk (Grade 0) & 0 \\
& Superficial ulcers (Grade I) & $78(4 I . I)$ \\
& Deep ulcers (Grade 2) & $89(46.8)$ \\
& Abscessed Deep ulcers (Grade 3) & $16(8.4)$ \\
& Limited gangrene (Grade 4) & $7(3.7)$ \\
& Extensive gangrene (Grade 5) & 0 \\
\hline
\end{tabular}

used and the results only showed the relation between a type of other complications (OC) in the diabetic patients with ulcer severity $(P=0.02)$. In order to exactly determine the type of relation between the diabetes symptoms with foot ulcer severity, the correlation table of chi-square test was used which had the most effect on the surface ulcer in patients and the most effective symptoms on the severity of the foot ulcer was cardiovascular diseases (Table 7).

\section{Discussion}

This study was conducted with the aim of the investigation of the awareness levels and the self-care function in the DFU patient and also the relation of the DFU severity with demographic characteristics, awareness, and the patients' self-care function. $57.4 \%$ of the subjects were women and the average age of the subjects was 53.13 \pm 11.65 years. The minimum age of the diabetes diagnosis in patients with DFU was reported as 32 years; It is obviously the indicator of the patient with the foot ulcer in the workforce of the community which besides health and medical costs, it also incurs costs of the withdrawal of the active fore of the community. Various studies have also reported the average age of patients with DFU as between 40-55 years. ${ }^{19,21,23}$ There is no significant reason for DFU incidence in middle-age persons but this can be due to the higher prevalence of diabetes in middle-age than in other age groups. In addition, although the quality of diabetes care in 
Table 3 Function and Awareness in Self-Care

\begin{tabular}{|c|c|c|c|c|c|}
\hline Parameters & Values & Mean士SD & Minimum & Maximum & Median \\
\hline \multirow[t]{4}{*}{ Awareness } & About Diabetes & $2.91 \pm 1.78$ & 0 & 7 & 4 \\
\hline & About exercise and physical function & $1.73 \pm 0.87$ & 0 & 4 & 2 \\
\hline & About Diet & $2.36 \pm 1.01$ & 1 & 5 & 2 \\
\hline & Total & $6.99 \pm 2.76$ & 2 & 15 & 7 \\
\hline \multirow[t]{6}{*}{ Function } & Diet & $13.15 \pm 2.6 \mid$ & 9 & 24 & 13 \\
\hline & Exercise and physical function & $13.10 \pm 2.70$ & 7 & 21 & 13 \\
\hline & Control of early complications & $|3.1| \pm 2.7$ & 8 & 20 & 13 \\
\hline & Control of late complications & $\mathrm{II} .0 \mathrm{I} \pm 2.74$ & 6 & 20 & 11 \\
\hline & Foot care & $11.83 \pm 3.16$ & 6 & 21 & 11 \\
\hline & Total & $62.22 \pm 9.92$ & 48 & 94 & 60 \\
\hline
\end{tabular}

Table 4 Relationship Between Quantitative Variables with Awareness and Function (Spearman Test)

\begin{tabular}{|l|l|l|}
\hline Parameter & Awareness & Function \\
\hline Age & $P=0.000 * * r=-0.390$ & $P=0.921 \quad r=0.007$ \\
Illness duration & $P=0.008 * * r=-0.193$ & $P=0.324 r=0.070$ \\
\hline
\end{tabular}

Note: $* *$ Significant at 0.01 .

women appears to be higher than in men, the prevalence of DFU in women is higher than in men, which may be due to cultural differences in access to healthcare. Furthermore, in recent studies the duration of diabetes in patients with DFU has been noted as 11-16 years, ${ }^{19,23,24}$ but in the Jae-Seung Yun et $\mathrm{al}^{21}$ study this time has been reported as 6.1 years. This time is important to learn about diabetes and foot care. A family history of diabetes was found in 56 patients and 19 of them (32.75\%) reported complications of diabetes in their family. This can be due to the impact of family hygiene status on family members in the same way and can be controlled by home-visits. About the effect of inheritance, more studies are needed. According to the Wagner ulcer scale, $41 \%$ of the ulcers were classified as grade $1,46.8 \%$ as grade $2,8.4 \%$ as grade 3 , and $3.7 \%$ as grade 4 . In the Jin Hwang et $\mathrm{al}^{25}$ study, $35 \%$ of the subjects had an ulcer of grade $1,10 \%$ grade $2,26 \%$ grade $3,28 \%$ grade 4 , and $1 \%$ grade 5. This difference between the frequency of patients at degrees 3 and 4 can be due to the difference in therapeutic methods and scar control teams among different studies. In the Kermanshah Diabetes center, a wound specialist team is used to control the ulcers of patients. The results of this study show that $58.4 \%$ of the subjects had obtained less than half of the awareness score and $92.6 \%$ of them had also received less than half of the self-care function. The large number of subjects with a score of less than half of a questionnaire score shows the low self-care function and the need for health training and planning; although there was no relation between the self-care function with diabetic foot ulcer severity $(P>0.05)$. There was also no meaningful relation between awareness level and diabetic foot ulcer severity $(P>0.05)$. This lack of relation can be due to the stronger relation between diabetic foot ulcer severity and hygiene and physical factors after the disease and the effect of awareness and function would be only in the stage of the incidence of the disease. Although the results of the present study confirmed the effectiveness of the relation between other complications and diabetic foot ulcer severity; there is more need to confirm this hypothesis. The results of the study found the relation between the age and the duration of diabetes with the patient's awareness $(P=0.008, P=0.000)$. This issue can be justified by receiving training and experience over time, but it also highlights that individuals of a younger age need more comprehensive training to improve awareness. There was also a relation between education level with awareness score and self-care function $(P=0.000, P=0.000)$. Twenty-six patients $(13.7 \%)$ with foot ulcer also had other complications of diabetes. The results of statistical analysis also showed the existence of a meaningful relation between the type of symptoms with foot ulcer severity $(P=0.02)$. It can be due to the effect of diabetes on patients in the same way. Jin Hwang et $\mathrm{al}^{25}$ also reported retinopathy in $90 \%$ of the patients with diabetic foot ulcer in his research, but 
Table 5 Relationship Between Qualitative Variables with Awareness and Function (KW \& UMW Test)

\begin{tabular}{|c|c|c|c|c|c|c|}
\hline \multirow[t]{2}{*}{ Test } & \multicolumn{2}{|l|}{ Parameters } & \multicolumn{2}{|l|}{ Mean Rank } & \multicolumn{2}{|l|}{ Statistics } \\
\hline & & & Awareness & Function & Awareness & Function \\
\hline \multirow[t]{10}{*}{ U Mann-Whitney } & Gender & Female & 94.78 & 91.22 & $P=0.876 Z=-0.156$ & $P=0.354 \quad Z=-0.927$ \\
\hline & & Male & 96.03 & 98.68 & & \\
\hline & Location & City & 96.41 & 94.41 & $P=0.703 \quad Z=-0.381$ & $P=0.652 Z=-0.450$ \\
\hline & & Village & 93.01 & 98.46 & & \\
\hline & Family History of Diabetes & Yes & 90.81 & 90.28 & $P=0.432 Z=-0.785$ & $P=0.385 Z=-0.868$ \\
\hline & & No & 97.56 & 97.79 & & \\
\hline & Diabetes Complications in Family & Yes & 86.26 & 78.13 & $P=0.437 Z=-0.778$ & $P=0.146 Z=-1.454$ \\
\hline & & No & 96.53 & 97.43 & & \\
\hline & OC & Yes & 85.25 & 98.13 & $P=0.303 Z=-1.031$ & $P=0.792 Z=-0.263$ \\
\hline & & No & 97.13 & 95.08 & & \\
\hline \multirow[t]{28}{*}{ Kruskal Wallis } & Type of OC & Cardiovascular & 109.14 & 112.18 & $P=0.176 K^{2}=6.329$ & $P=0.635 K^{2}=2.551$ \\
\hline & & Comp. & & & & \\
\hline & & Eye Comp. & 61.25 & 104.00 & & \\
\hline & & Renal Comp. & 30.75 & 97.75 & & \\
\hline & & Other Comp. & 83.86 & 71.14 & & \\
\hline & Income (USD/Month) & $<300$ & 92.43 & 92.84 & $P=0.129 \mathrm{~K}^{2}=4.099$ & $P=0.274 K^{2}=2.586$ \\
\hline & & $300-400$ & 117.04 & 110.63 & & \\
\hline & & $>400$ & 96.00 & 112.10 & & \\
\hline & Job & Employee & 125.54 & 109.16 & $P=0.002 * K^{2}=26.192$ & $P=0.497 K^{2}=8.378$ \\
\hline & & Self-Employment & 106.70 & 74.90 & & \\
\hline & & Workless & 81.70 & 103.60 & & \\
\hline & & Retired & 68.03 & 92.78 & & \\
\hline & & Military & 116.60 & 69.10 & & \\
\hline & & Home Made & 90.39 & 93.49 & & \\
\hline & & Student & 107.69 & 120.88 & & \\
\hline & & Farmer-Herdsman & 62.73 & 91.40 & & \\
\hline & & Driver & 80.06 & 103.63 & & \\
\hline & & Other & 132.50 & 103.00 & & \\
\hline & Education & Illiterate & 90.81 & 80.44 & $P=0.000 * K^{2}=35.519$ & $P=0.000^{*} K^{2}=30.007$ \\
\hline & & Elementary & 79.36 & 88.72 & & \\
\hline & & Secondary & 91.73 & 87.12 & & \\
\hline & & Education & & & & \\
\hline & & High School & 107.87 & 115.39 & & \\
\hline & & College & 172.69 & 160.78 & & \\
\hline & Marriage & Single & 99.49 & 95.74 & $P=0.315 K^{2}=3.545$ & $P=0.909 K^{2}=0.542$ \\
\hline & & Married & 79.41 & 100.47 & & \\
\hline & & Divorced & 82.21 & 87.84 & & \\
\hline & & Widow & 86.00 & 99.31 & & \\
\hline
\end{tabular}

Note: *Significant at 0.05 .

there was no relation between retinopathy problem and ulcer severity. Limited studies have been done on diabetic ulcer foot severity, but in these studies the factors such as age, PAD, hypertriglyceridemia, hypertension, BMI, FBS, and glucose two hours after fasting have been shown to be related to ulcer severity. ${ }^{18,19}$ Taqipoor et $\mathrm{al}^{12}$ have stated that mechanical factors such as musculoskeletal disorders and balance disorders also relate to diabetic foot ulcers. As this subject is novel, more comprehensive studies are recommended 
Table 6 Relationship Between Quantitative Variables with Severity of Foot Ulcer

\begin{tabular}{|l|l|l|}
\hline \multirow{2}{*}{ Parameter } & \multicolumn{2}{|l|}{ Severity of Foot Ulcer } \\
\cline { 2 - 3 } & H & P-value \\
\hline Function & 0.89 & 0.82 \\
Awareness & 1.4 & 0.70 \\
Age & 4.04 & 0.25 \\
Durationof illness & 3.16 & 0.36 \\
\hline
\end{tabular}

to study the effective factors on diabetic ulcer foot severity in other environments.

\section{Conclusion}

Since awareness and function of patients in self-care is less than average, the increasing awareness of patients and empowering them through appropriate training can be effective in preventing diabetic foot ulcers. This is all the more

Table 7 Relationship Between Qualitative Variables With Severity of Foot Ulcer

\begin{tabular}{|c|c|c|c|c|c|c|}
\hline \multirow[t]{2}{*}{ Parameter } & \multirow[t]{2}{*}{ Values } & \multicolumn{4}{|c|}{ Severity of Foot Ulcer } & \multirow[t]{2}{*}{ Statistics } \\
\hline & & GI & G2 & G3 & G4 & \\
\hline Gender & $\begin{array}{l}\text { Female } \\
\text { Male }\end{array}$ & $\begin{array}{l}41(37.6) \\
37(45.7)\end{array}$ & $\begin{array}{l}51(46.8) \\
38(3.7)\end{array}$ & $\begin{array}{l}13(11.9) \\
3(3.7)\end{array}$ & $\begin{array}{l}4(3.7) \\
3(3.7)\end{array}$ & $P=0.21 x^{2}=4.46$ \\
\hline Location & $\begin{array}{l}\text { City } \\
\text { Village }\end{array}$ & $\begin{array}{l}57(41.0) \\
21(41.2)\end{array}$ & $\begin{array}{l}67(48.2) \\
22(43.1)\end{array}$ & $\begin{array}{l}11(7.9) \\
5(9.8)\end{array}$ & $\begin{array}{l}4(2.9) \\
3(5.9)\end{array}$ & $P=0.73 x^{2}=1.27$ \\
\hline Education & $\begin{array}{l}\text { Illiterate } \\
\text { Elementary } \\
\text { Secondary Education } \\
\text { High School } \\
\text { College }\end{array}$ & $\begin{array}{l}13(37.1) \\
27(39.1) \\
21(41.2) \\
11(57.9) \\
6(37.5)\end{array}$ & $\begin{array}{l}17(48.6) \\
35(50.7) \\
23(45.1) \\
6(31.6) \\
8(50.0)\end{array}$ & $\begin{array}{l}4(11.4) \\
5(7.2) \\
5(9.8) \\
1(5.3) \\
1(6.3)\end{array}$ & $\begin{array}{l}\text { I (2.9) } \\
2(2.9) \\
2(3.9) \\
\text { I(5.3) } \\
\text { I (6.3) }\end{array}$ & $P=0.97 x^{2}=4.33$ \\
\hline Marriage & $\begin{array}{l}\text { Single } \\
\text { Married } \\
\text { Divorced } \\
\text { Widow }\end{array}$ & $\begin{array}{l}62(42.2) \\
7(43.8) \\
6(31.6) \\
3(37.5)\end{array}$ & $\begin{array}{l}69(46.9) \\
7(43.8) \\
10(52.6) \\
3(37.5)\end{array}$ & $\begin{array}{l}12(8.2) \\
\text { I }(6.3) \\
2(10.5) \\
\text { I }(12.5)\end{array}$ & $\begin{array}{l}4(2.7) \\
\text { I }(6.3) \\
\text { I }(5.3) \\
\text { I }(12.5)\end{array}$ & $P=0.93 x^{2}=3.66$ \\
\hline Job & $\begin{array}{l}\text { Employee } \\
\text { Self-Employment } \\
\text { Workless } \\
\text { Retired } \\
\text { Military } \\
\text { Home Made } \\
\text { Student } \\
\text { Farmer-Herdsman } \\
\text { Driver } \\
\text { Other }\end{array}$ & $\begin{array}{l}17(50.0) \\
8(40.0) \\
0 \\
11(55.0) \\
1(20.0) \\
25(35.2) \\
6(75.0) \\
5(33.3) \\
4(50.0) \\
I(25.0)\end{array}$ & $\begin{array}{l}13(38.2) \\
10(50.0) \\
4(80.0) \\
9(45.0) \\
4(80.0) \\
35(49.3) \\
2(25.0) \\
6(40.0) \\
3(37.5) \\
3(75.0)\end{array}$ & $\begin{array}{l}4(11.8) \\
\text { I }(5.0) \\
I(20.0) \\
0 \\
0 \\
7(9.9) \\
0 \\
3(20.0) \\
0 \\
0\end{array}$ & $\begin{array}{l}0 \\
I(5.0) \\
0 \\
0 \\
0 \\
4(5.6) \\
0 \\
1(6.7) \\
1(12.5) \\
0\end{array}$ & $P=0.51 x^{2}=26.04$ \\
\hline Income (USD/Month) & $\begin{array}{l}<300 \\
300-400 \\
>400\end{array}$ & $\begin{array}{l}64(39.5) \\
13(56.5) \\
1(20.0)\end{array}$ & $\begin{array}{l}78(48.1) \\
8(34.8) \\
3(60.0)\end{array}$ & $\begin{array}{l}14(8.6) \\
2(8.7) \\
0\end{array}$ & $\begin{array}{l}6(3.7) \\
0 \\
I(20.0)\end{array}$ & NA \\
\hline Family History of Diabetes & $\begin{array}{l}\text { Yes } \\
\text { No }\end{array}$ & $\begin{array}{l}25(43.1) \\
53(40.2)\end{array}$ & $\begin{array}{l}28(48.3) \\
61(46.2)\end{array}$ & $\begin{array}{l}5(8.6) \\
11(8.3)\end{array}$ & $\begin{array}{l}0 \\
7(5.3)\end{array}$ & $P=0.36 x^{2}=3.20$ \\
\hline Diabetes Complications in Family & $\begin{array}{l}\text { Yes } \\
\text { No }\end{array}$ & $\begin{array}{l}6(31.6) \\
72(42.1)\end{array}$ & $\begin{array}{l}10(52.6) \\
79(46.2)\end{array}$ & $\begin{array}{l}3(15.8) \\
13(7.6)\end{array}$ & $\begin{array}{l}0 \\
7(4.1)\end{array}$ & $P=0.43 x^{2}=2.75$ \\
\hline OC & $\begin{array}{l}\text { Yes } \\
\text { No }\end{array}$ & $\begin{array}{l}13(50.0) \\
65(39.6)\end{array}$ & $\begin{array}{l}9(34.6) \\
80(48.8)\end{array}$ & $\begin{array}{l}1(3.8) \\
15(9.1)\end{array}$ & $\begin{array}{l}3(11.5) \\
4(2.4)\end{array}$ & $P=0.06 * x^{2}=7.34$ \\
\hline Type of OC & $\begin{array}{l}\text { Cardiovascular Comp. } \\
\text { Eye Comp. } \\
\text { Renal Comp. } \\
\text { Other Comp. }\end{array}$ & $\begin{array}{l}4(36.4) \\
4(66.7) \\
0 \\
5(71.4)\end{array}$ & $\begin{array}{l}5(45.5) \\
2(33.3) \\
2(100.0) \\
0\end{array}$ & $\begin{array}{l}1(9.1) \\
0 \\
0 \\
0\end{array}$ & $\begin{array}{l}1(9.1) \\
0 \\
0 \\
2(28.6)\end{array}$ & NA \\
\hline
\end{tabular}

Note: *Significant at 0.05 . 
important when the results show that there is a relationship between age and education of patients with their awareness and function, and those with the lower age and education need more training. In addition, a treatment plan to help control other complications of diabetes is helpful. This study requires further research to identify other aspects of the factors affecting the DFU, as well as further information to confirm or contrast with the results of this study.

\section{Abbreviations}

DFU, Diabetic Foot Ulcer; BS, Blood Sugar; KUMS, Kermanshah University of Medical Sciences; PAD, Peripheral Atrial Disease; KW, Kruskal Wallis; UMW, U Mann-Whitney.

\section{Data Sharing Statement}

The identified datasets used during the current study are available from the corresponding author on reasonable request.

\section{Ethics and Consent Statement}

This study was carried out following permission from the Ethics Committee, Department of Research and Technology, Kermanshah University of Medical Sciences (approval number, IR.KUMS.REC.1397.025). This study was conducted in accordance with the Declaration of Helsinki. The participants were thoroughly informed about the objectives of the study and how to fill out the questionnaires. They were also ensured about the confidentiality of their information.

\section{Acknowledgments}

This research project was approved in the Kermanshah University of Medical Sciences with approval number 97786. The financial budget of this project was provided by Kermanshah University of Medical Sciences. The authors wish to thank the Department of Research and Technology of the university and officials of Imam Reza Hospital for the opportunity to carry out the study.

\section{Author Contributions}

All authors contributed to designing the study, drafting and revising the article, wrote the final report and manuscript, gave final approval of the version to be published, and agree to be accountable for all aspects of the work. PAS, $\mathrm{AG}$, and MJ collected the data, and it was analyzed by SM, AG, and PAS.

\section{Funding}

The study was funded by Kermanshah University of Medical Sciences.

\section{Disclosure}

The authors declare that they have no conflicts of interest.

\section{References}

1. Zimmet P, Alberti KG, Magliano DJ, Bennett PH. Diabetes mellitus statistics on prevalence and mortality: facts and fallacies. Nat Rev Endocrinol. 2016;12(10):616-622. doi:10.1038/nrendo.2016.105

2. IDF Diabetes Atlas 9th edition. 2019. Available from: https://diabete satlas.org/en/. Accessed December 13, 2019.

3. World Health Organiztion. Global Report on Diabetes. Geneva: World Health Organization; 2016.

4. Ochoa-gonzalez F, Cervantes-villagrana AR, Fernandez-ruiz JC, et al. Metformin induces cell cycle arrest, reduced proliferation, wound healing impairment in vivo and is associated to clinical outcomes in diabetic foot ulcer patients. PLoS One. 2016;11(3):e0150900. doi:10.1371/journal.pone. 0150900

5. Chuan F, Tang K, Jiang P, Zhou B, He X. Reliability and validity of the perfusion, extent, depth, infection and sensation (PEDIS) classification system and score in patients with diabetic foot ulcer. PLoS One. 2015;10(4):e0124739-e0124739. doi:10.1371/journal.pone.0124739

6. Amin N, Doupis J. Diabetic foot disease: from the evaluation of the "foot at risk" to the novel diabetic ulcer treatment modalities. World J Diabetes. 2016;7(7):153-164. doi:10.4239/wjd.v7.i7.153

7. Alavi A, Sibbald R, Mayer D, et al. Diabetic foot ulcers Part I. Pathophysiology and prevention. J Am Acad Dermatol. 2014;70:1. e1-1.e18. doi:10.1016/j.jaad.2013.06.055

8. Sargen MR, Hoffstad O, Margolis DJ. Geographic variation in medicare spending and mortality for diabetic patients with foot ulcers and amputations. J Diabetes Complications. 2013;27(2):128-133. doi:10.10 16/j.jdiacomp.2012.09.003

9. Gordois A, Scuffham P, Shearer A, Oglesby A, Tobian JA. The health care costs of diabetic peripheral neuropathy in the US. Diabetes Care. 2003;26(6):1790-1795. doi:10.2337/diacare.26.6.1790

10. Gordois A, Scuffham P, Shearer A, Oglesby A. The healthcare costs of diabetic peripheral neuropathy in the UK. (Cost-of-illness study). Diabetes Care. 2003;26(6):1790-5.

11. Yazdanpanah L, Nasiri M, Adarvishi S. Literature review on the management of diabetic foot ulcer. World J Diabetes. 2015;6 (1):37-53. doi:10.4239/wjd.v6.i1.37

12. Taghipour M, Abi Kordadeh E, Eslami M. Review of biomechanical parameters of diabetic foot ulcers. Razi J Med Sci. 2016;23 (144):51-67.

13. Zhang P, Lu J, Jing Y, Tang S, Zhu D, Bi Y. Global epidemiology of diabetic foot ulceration: a systematic review and meta-analysis. Ann Med. 2016;49:1-21. doi:10.1080/07853890.2016.1211789

14. Atosona A, Larbie C. Prevalence and determinants of diabetic foot ulcers and lower extremity amputations in three selected tertiary hospitals in Ghana. J Diabetes Res. 2019;2019:9. doi:10.1155/2019/7132861

15. Boulton A, Vileikyte L, Ragnarson-tennvall G, Apelqvist J. The global burden of diabetic foot disease. Lancet. 2005;366:1719-1724. doi:10.1016/S0140-6736(05)67698-2

16. Taher M, Abredari H, Karimy M, Rahmati M, Atarod M, Azaepira H. The assessment of social support and self-care requisites for preventing diabetic foot ulcer in diabetic foot patients. $J$ Educ Community Health. 2016;2(4):34-40. doi:10.21859/jech-02045

17. Al-rubeaan K, Al Derwish M, Ouizi S, et al. Diabetic foot complications and their risk factors from a large retrospective cohort study. PLoS One. 2015;10(5):e0124446-e0124446. doi:10.1371/journal.pone.0124446 
18. Pemayun TGD, Naibaho RM, Novitasari D, Amin N, Minuljo TT. Risk factors for lower extremity amputation in patients with diabetic foot ulcers: a hospital-based case-control study. Diabet Foot Ankle. 2015;6:29629. doi:10.3402/dfa.v6.29629

19. Moeini M, Shahriari M, Yousefi H, Esfandiari J, Babaahmadi M. An investigation on the wound severity and its association with predisposing factors in patients with diabetic foot. J Clin Nurs Midwifery. 2017;5:4.

20. Farsi J-M, Ebadi AZ. Application of health belief model in change of self care behaviors of diabetic patients. Iran J Nurs. 2009;22 (61):61-72.

21. Yun J-S, Cha S-A, Lim T-S, et al. Cardiovascular autonomic dysfunction predicts diabetic foot ulcers in patients with Type 2 diabetes without diabetic polyneuropathy. Medicine (Baltimore). 2016;95(12): e3128-e3128. doi:10.1097/MD.0000000000003128
22. Mohammed SI, Mikhael EM, Ahmed FT, Al-tukmagi HF, Jasim AL. Risk factors for occurrence and recurrence of diabetic foot ulcers among Iraqi diabetic patients. Diabet Foot Ankle. 2016;7:29605. doi:10.3402/dfa.v7.29605

23. Wukich DK, Hobizal KB, Sambenedetto TL, Kirby K, Rosario BL. Outcomes of osteomyelitis in patients hospitalized with diabetic foot infections. Foot Ankle Int. 2016;37(12):1285-1291. doi:10.1177/ 1071100716664364

24. Tabur S, Eren MA, Çelik Y, et al. The major predictors of amputation and length of stay in diabetic patients with acute foot ulceration. Wien Klin Wochenschr. 2015;127(1-2):45-50. doi:10.1007/s00508-014-0630-5

25. Hwang DJ, Lee KM, Park MS, et al. Association between diabetic foot ulcer and diabetic retinopathy. PLoS One. 2017;12(4):e0175270e0175270. doi:10.1371/journal.pone.0175270

\section{Publish your work in this journal}

Diabetes, Metabolic Syndrome and Obesity: Targets and Therapy is an international, peer-reviewed open-access journal committed to the rapid publication of the latest laboratory and clinical findings in the fields of diabetes, metabolic syndrome and obesity research. Original research, review, case reports, hypothesis formation, expert opinion and commentaries are all considered for publication. The manuscript management system is completely online and includes a very quick and fair peer-review system, which is all easy to use. Visit http://www.dovepress.com/testimonials.php to read real quotes from published authors.

Submit your manuscript here: https://www.dovepress.com/diabetes-metabolic-syndrome-and-obesity-targets-and-therapy-journal 